\title{
USO DO PLANEJAMENTO EXPERIMENTAL PARA AVALIAR A PRODUÇÃO DE ENZIMAS CELULOLÍTICAS POR CULTIVO EM ESTADO SÓLIDO
}

\author{
J. H. S. OLIVEIRA ${ }^{1}$, M. T. $\operatorname{COSTA}^{1}$ e A. K. S. ABUD ${ }^{2}$ \\ ${ }^{1}$ Universidade Federal de Alagoas, Centro de Tecnologia \\ ${ }^{2}$ Universidade Federal de Sergipe, Departamento de Tecnologia de Alimentos \\ E-mail para contato: jhenriquesoliveira@hotmail.com
}

\begin{abstract}
RESUMO - A biotransformação de resíduos agroindustriais em compostos de alto valor agregado a partir da fermentação semi-sólida é uma das tecnologias de destaque na obtenção de enzimas celulolíticas, visando sua aplicação na hidrólise para produção de etanol de segunda geração. O trabalho avalia o uso simultâneo da casca de maracujá e do sabugo de milho como substratos para a produção das enzimas avicelase e xilanase na fermentação semi-sólida com o fungo Aspergillus niger. Para maior expressão das enzimas, realizou-se um planejamento experimental $2^{3}$, com repetições no ponto central, tendo como variáveis o $\mathrm{pH}$, a umidade e a proporção dos resíduos. O melhor ajuste foi para a atividade de xilanase, com significância para a umidade e o pH. A máxima produção ocorreu na condição de maior teor de umidade, menor $\mathrm{pH}$ e menor proporção de casca de maracujá em relação ao sabugo de milho, obtendo-se em torno de $35 \mathrm{U} / \mathrm{g}$ de atividade para ambas as enzimas, resultados expressivos quando comparados à literatura.
\end{abstract}

\section{INTRODUÇÃO}

Segundo dados da Food and Agriculture Organization (FAO), o Brasil é o terceiro maior produtor mundial de frutas, atrás apenas da China e da Índia. A região Nordeste foi responsável pela maior parte da produção de frutas tropicais, destacando-se o abacaxi, o abacate, a banana, o caju, o coco, o mamão, a manga, o maracujá, a uva, a acerola e a goiaba, sendo favorecida pelo clima, solo, localização e disponibilidade de água para irrigação, aliada ao preço atrativo da terra e à disponibilidade e custo da mão-de-obra, conferem a esta região a liderança na produção e exportação de frutas tropicais (Santos et al., 2008).

Além do consumo in natura, a crescente demanda pelos sucos, geléias e doces de frutas exóticas no mercado nacional e internacional torna necessário o desenvolvimento de pesquisas para o aproveitamento integral dos frutos. Aliado a isto, a crescente preocupação com possíveis impactos ambientais e o elevado índice de perdas e desperdícios gerados na indústria de processamento de alimentos tem levado à necessidade da utilização eficiente e do aproveitamento integral dos recursos agrícolas (Pandey et al., 2000). 


\section{9 a 22 de outubro de 2014 \\ Florianópolis/SC}

$\mathrm{Na}$ área de bioprocessos, o interesse no uso de resíduos agroindustriais tem sido crescente, utilizando-o como substrato para a incorporação em alimentos e produção de diversas moléculas com alto valor agregado, a exemplo de proteínas microbianas, ácidos orgânicos, etanol, enzimas e metabólitos secundários biologicamente ativos. Assim, além de ser uma alternativa economicamente viável, obtendo compostos de alto valor agregado para uso nas indústrias de alimentos, cosmética e farmacêutica, ajuda a resolver o problema ambiental decorrente do seu acúmulo na natureza (Laufenberg et al., 2003, Lousada Junior et al., 2006).

Neste cenário, a fermentação semi-sólida para enriquecimento protéico de resíduos, eliminação de substâncias recalcitrantes por destoxificação e produção de compostos de interesse comercial, como enzimas e diferentes metabólitos, merece destaque, sendo uma das tecnologias empregadas e amplamente utilizada para a obtenção de enzimas, aromas, corantes e outras substâncias de valor agregado na indústria de alimentos, gerando altos rendimentos e menores custos de extração e purificação em relação à fermentação submersa (Couto e Sanromán, 2006).

A produção de enzimas neste processo é consequência da demanda por insumos de menor custo, uma vez que o mercado mundial para uso industrial é estimado em 625 milhões de dólares, dos quais $62 \%$ das enzimas produzidas são utilizadas por indústrias alimentícias, na qual há a necessidade de que o microrganismo não secrete micotoxinas ou outras substâncias tóxicas e nem seja patogênico (Fungaro et al., 1994; Santos et al., 2005; Uenojo; Pastore, 2007). Também são empregadas em grande escala na indústria têxtil (amilase, celulase, pectinase), de papel (lipase, xilanase, oxiredutases) e de detergentes (celulase, lipase, protease) (Van Beilen, 2002; Oliveira, 2010). Como a maioria dos rejeitos agroindustriais contém grande quantidade de compostos como celulose, hemicelulose, pectina e outros, não há necessidade de grandes complementações nutricionais para o adequado desenvolvimento microbiano, pois funcionam como indutores para a produção de enzimas extracelulares, tais como celulases, xilanases, pectinases e outras (Coelho et al., 2001).

As maiores expectativas para a viabilização do etanol celulósico no longo prazo estão depositadas na possibilidade de se utilizar a máquina bioquímica de microrganismos (fungos e bactérias) para desmontar a parede celular. Para chegar à celulose, que é o principal composto da parede celular, os fungos precisam hidrolisar as outras hemiceluloses que recobrem as microfibrilas e, para isto, são necessários verdadeiros arsenais enzimáticos, como celulases e outras hidrolases, sendo pertinente o estudo do poderio enzimático dos fungos, bem como as estruturas finas de enzimas hidrolíticas, para utilizá-las a nosso favor.

O presente trabalho buscou avaliar o uso simultâneo da casca de maracujá e do sabugo de milho como substratos para a produção das enzimas avicelase e xilanase na fermentação semisólida com o fungo Aspergillus niger.

\section{MATERIAIS E MÉTODOS}

O microrganismo utilizado foi a cepa de Aspergillus niger isolada do solo, gentilmente cedida pelo BIOSE da Escola de Química da Universidade Federal do Rio de Janeiro (EQ/UFRJ), 


\section{9 a 22 de outubro de 2014 \\ Florianópolis/SC}

mantidos em tubos inclinados com ágar batata dextrose (PDA), a $4^{\circ} \mathrm{C}$. A solução mineral utilizada é composta por (g/L): $\left(\mathrm{NH}_{4}\right)_{2} \mathrm{SO}_{4}, 10 ; \mathrm{MnSO}_{4}, 0,005 ; \mathrm{MgSO}_{4} .7 \mathrm{H}_{2} \mathrm{O}, 1 ; \mathrm{FeSO}_{4} .7 \mathrm{H}_{2} \mathrm{O}$, 0,$005 ; \mathrm{KH}_{2} \mathrm{PO}_{4}, 3 ; \mathrm{ZnSO}_{4}, 0,005$ e $\mathrm{CaCl}_{2}, 0,5$.

Os resíduos foram colocados em frascos Erlenmeyer de $250 \mathrm{~mL}$, juntamente com a solução mineral, cobertos com tampão de algodão e autoclavados a $121^{\circ} \mathrm{C}$ por 15 min sendo, posteriormente, inoculados a uma taxa de $3.10^{7}$ esporos/g de substrato seco. As fermentações foram conduzidas a $30^{\circ} \mathrm{C}$ em estufa bacteriológica por 4 dias, coletando-se um frasco de material fermentado a cada 24 horas.

Para a extração da enzima, adicionou-se $50 \mathrm{~mL}$ de água gelada a cada frasco contendo a torta fermentada, sendo homogeneizado em shaker à $30^{\circ} \mathrm{C}$ por um período de 30 min e filtrado em gaze para a obtenção do extrato enzimático bruto, que foi centrifugado a $3000 \mathrm{rpm}$ por $10 \mathrm{~min}$ para a remoção de sólidos mais finos. O sobrenadante foi filtrado em papel de filtro qualitativo e armazenado em geladeira para posterior análise de atividade enzimática, $\mathrm{pH}$, açúcares redutores (AR) e redutores totais (ART).

As análises de $\mathrm{pH}$ foram feitas seguindo normas do Instituto Adolfo Lutz (2005). As produções enzimáticas foram expressas em unidades de atividade por grama de resíduo seco (U/g). As atividades de avicelase e xilanase foram realizadas conforme metodologias descritas por Martin et al. (2004) e Uenojo e Pastore (2007), em espectrofotômetro UV-visível, e acompanhadas por controles para descartar possíveis interferentes com os métodos de determinação. Os açúcares redutores liberados foram determinados pelo método de DNS (ácido3,5-dinitrosalicílico) segundo Miller (1959), utilizando-se uma curva padrão de glicose. A unidade de atividade enzimática (U/L) é expressa como a liberação de $1 \mu$ mol de açúcar por minuto por $\mathrm{mL}$ de enzima, sendo, em sequência, dividido pela concentração do resíduo e tempo de reação para se obter a atividade em $\mathrm{U} / \mathrm{g}$.

Para avaliar a eficiência do processo fermentativo realizou-se um planejamento experimental $2^{3}$ com repetições no ponto central, utilizando os resíduos de casca de maracujá e sabugo de milho, tendo como variáveis independentes o $\mathrm{pH}$, a umidade e a proporção dos resíduos. Na Tabela 1 estão presentes as condições experimentais do planejamento e na Tabela 2 ordem e codificação dos mesmos.

Tabela 1 - Variáveis independentes estudadas.

\begin{tabular}{cccc}
\hline Variáveis & $\mathbf{- 1}$ & $\mathbf{0}$ & $\mathbf{+ 1}$ \\
\hline Umidade (\%) & 55 & 70 & 85 \\
pH & 4,0 & 5,5 & 7,0 \\
Proporção (g:g) & $0,5: 1,5$ & $1,0: 1,0$ & $1,5: 0,5$ \\
\hline
\end{tabular}

O objetivo do planejamento foi analisar, de forma mais rápida, quais os fatores influenciam o processo de síntese das enzimas avicelase e xilanase. Os resíduos utilizados foram a casca de 
maracujá e o sabugo de milho, sendo as amostras coletadas após 24 e 72 h de fermentação.

Tabela 2 - Ordem dos experimentos codificados

\begin{tabular}{cccccccccccc}
\hline Ensaio & $\mathbf{1}$ & $\mathbf{2}$ & $\mathbf{3}$ & $\mathbf{4}$ & $\mathbf{5}$ & $\mathbf{6}$ & $\mathbf{7}$ & $\mathbf{8}$ & $\mathbf{9}$ & $\mathbf{1 0}$ & $\mathbf{1 1}$ \\
\hline Umidade & -1 & -1 & -1 & -1 & +1 & +1 & +1 & +1 & 0 & 0 & 0 \\
pH & -1 & -1 & +1 & +1 & +1 & +1 & -1 & -1 & 0 & 0 & 0 \\
Proporção & -1 & +1 & +1 & -1 & +1 & -1 & -1 & +1 & 0 & 0 & 0 \\
\hline
\end{tabular}

\section{RESULTADOS E DISCUSSÕES}

Na Figura 1 estão apresentados os resultados do consumo de açúcares e das atividades enzimáticas para os tempos 24 e 72 h de fermentação em cada condição do planejamento. Os resultados são ilustrados pela média e desvio padrão das análises em triplicata.
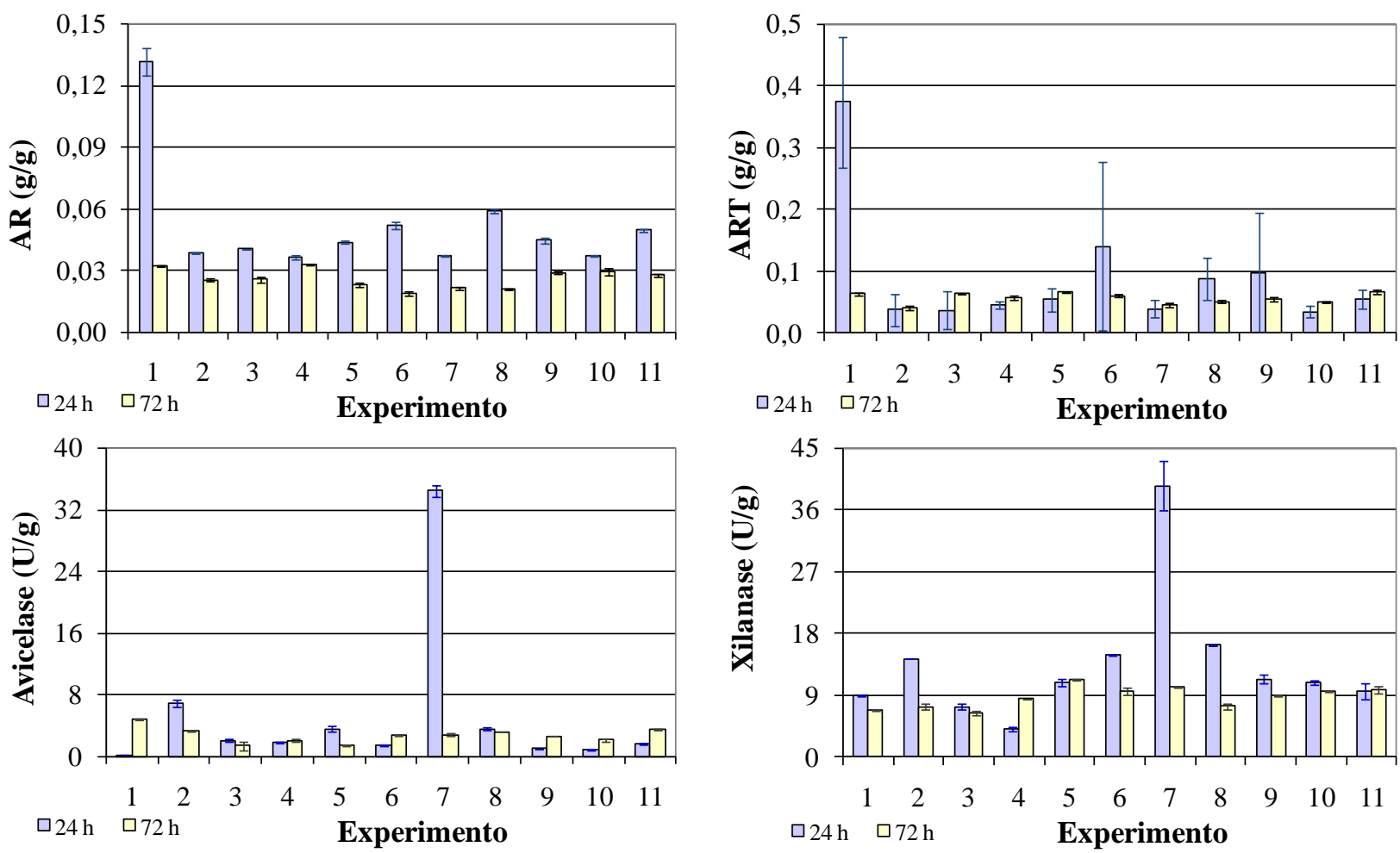

Figura 1 - Atividade enzimática nos tempos $24 \mathrm{~h}$ e $72 \mathrm{~h}$ de fermentação.

Os experimentos 1, 6 e 8 apresentaram os maiores consumos de açúcares redutores (AR). Para os açúcares redutores totais (ART), pode-se observar que algumas condições não houve consumo entre 24 e $72 \mathrm{~h}$ e, sim, aumento na concentração destes açúcares, possivelmente devido à hidrólise das enzimas presentes.

Verifica-se que o experimento 7, em 24 h de fermentação, possuiu atividades de avicelase e xilanase diferenciadas em relação às demais, com as repetições analíticas apresentando pequeno 
desvio. $\mathrm{O}$ experimento 7 tem como condição maior umidade, menor $\mathrm{pH}$ e menor proporção de casca de maracujá, indicando que o sabugo de milho é melhor indutor às sínteses enzimáticas avaliadas. A queda brusca em suas atividades, entre 24 e $72 \mathrm{~h}$, pode ser influenciada pelo substrato, onde não se observa grande consumo de AR e um ligeiro acréscimo de ART em $72 \mathrm{~h}$.

Nota-se, ainda, que a produção crescente de 24 para $72 \mathrm{~h}$ para a enzima avicelase ocorreu nos ensaios 1, 6, 9,10 e 11, estes três últimos referentes ao ponto central. Os ensaios 1 e 6 têm apenas em comum a maior proporção de sabugo de milho. Para a enzima xilanase, houve ligeiro acréscimo na síntese enzimática nos ensaios 4 e 5, que têm em comum o maior pH no estudo, 7,0. Outros experimentos que se destacam na produção de avicelase e xilanase são os ensaios 2 e 8, que possuem diferença apenas em seu teor de umidade, com menor $\mathrm{pH}$ e maior proporção da casca de maracujá, substrato rico em pectina. O menor tempo $(24 \mathrm{~h})$ mostrou-se como melhor instante para a síntese enzimática, indicando, também, superioridade na produção da enzima xilanase.

A influência das variáveis em 24 e 72 h de fermentação, a partir da análise de Pareto, pode ser observada nas Figuras 2 e 3, respectivamente.
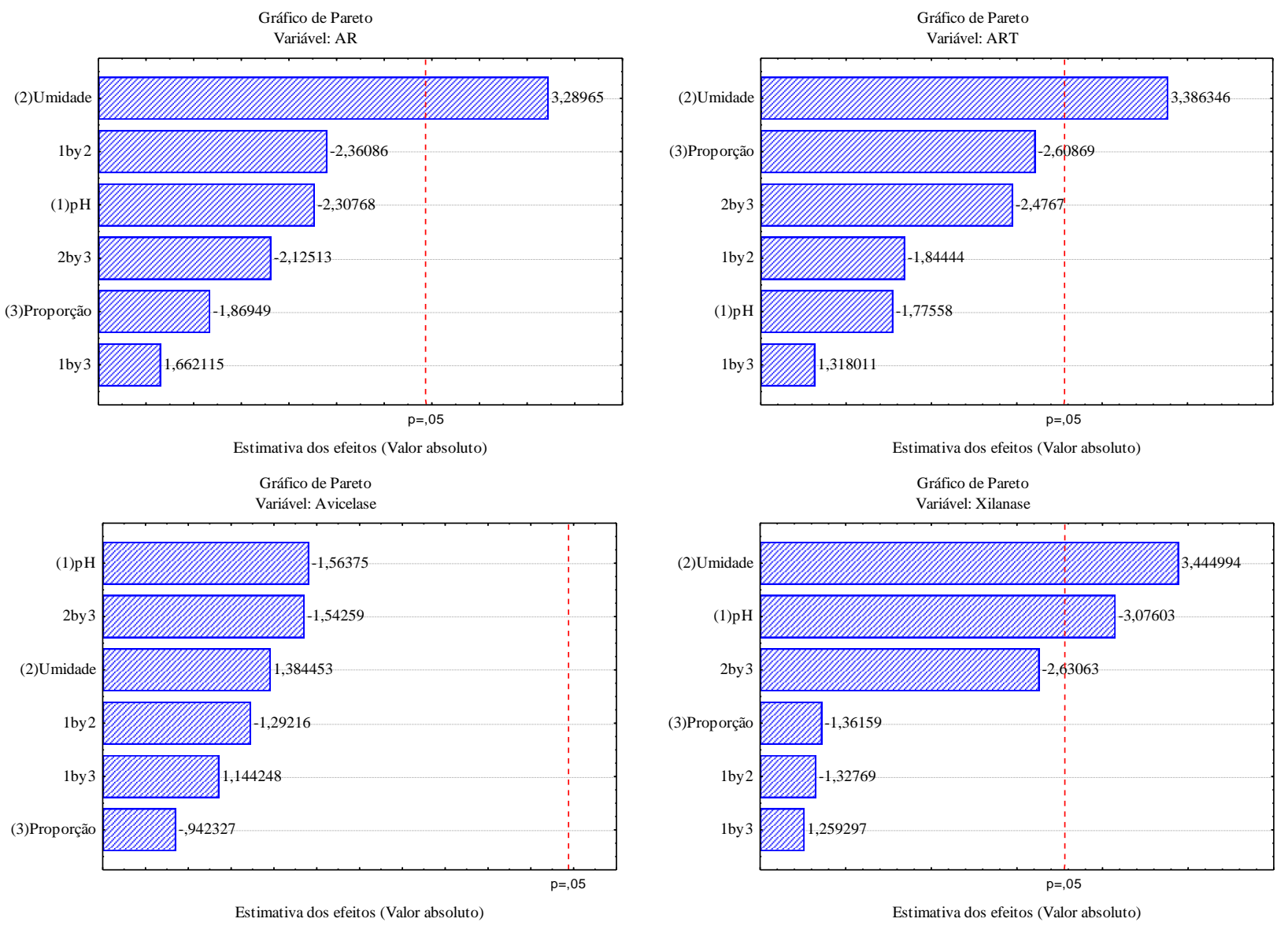

Figura 2 - Influência das variáveis em planejamento $2^{3}$, após 24 horas de fermentação. 
Após $24 \mathrm{~h}$ de fermentação, percebe-se que o aumento da umidade exerceu influência significativa na concentração de açúcares redutores (AR) e redutores totais (ART), bem como a atividade de xilanase. A síntese de xilanase também teve influência do $\mathrm{pH}$, sendo o menor valor em estudo o que gerou melhores produções. As variáveis estudadas não influenciaram a atividade de avicelase.
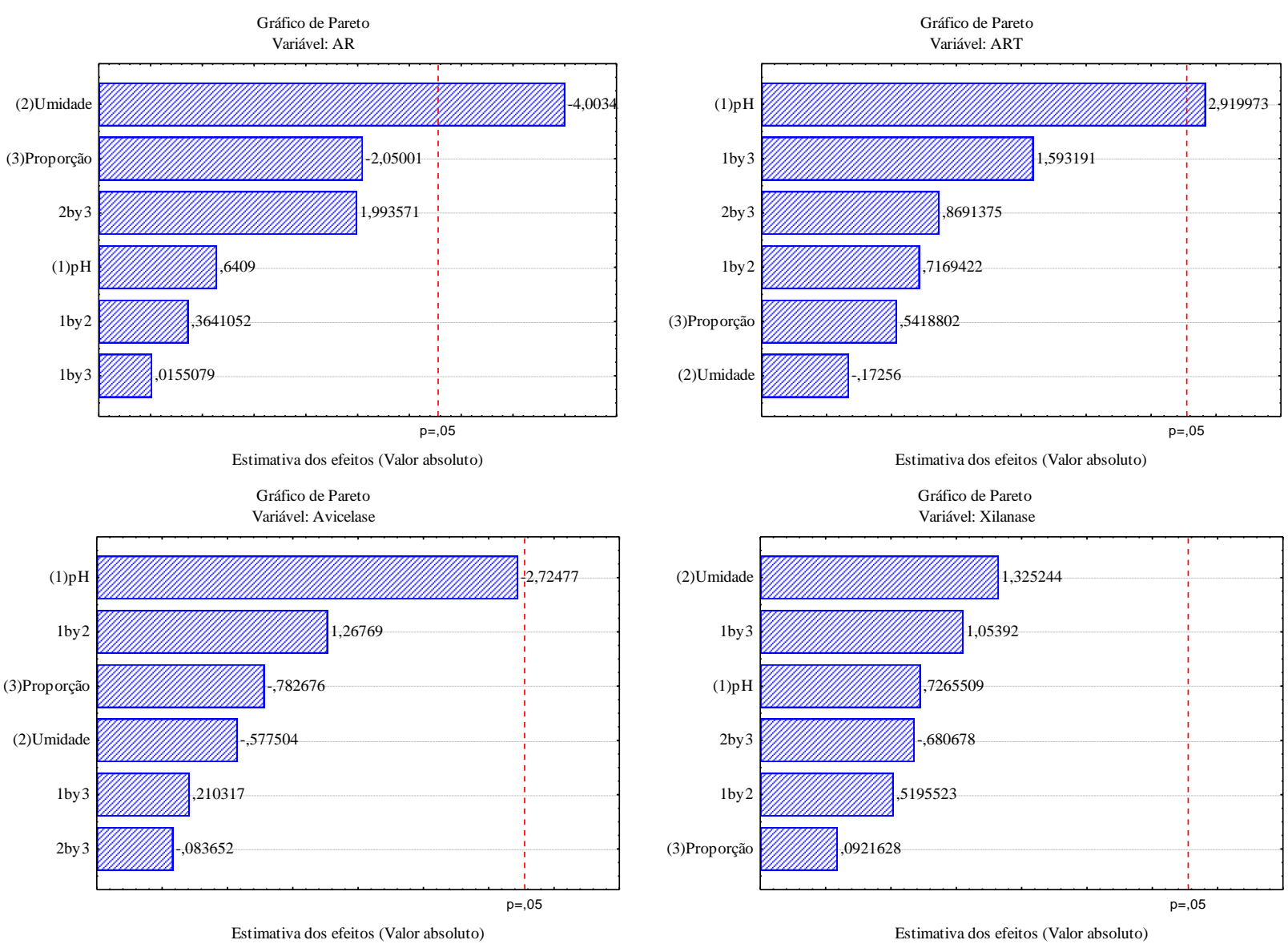

Figura 3 - Influência das variáveis em planejamento experimental $2^{3}$, após 72 horas de fermentação.

Após $72 \mathrm{~h}$ de fermentação, a umidade influenciou as concentrações de açúcares redutores (AR), sendo o menor teor o de maior o rendimento, enquanto que para os açúcares redutores totais (ART) o maior $\mathrm{pH}$ foi o de maior significância. Ao contrário da condição de ART, o menor valor de $\mathrm{pH}$ influenciou a síntese de avicelase, ao passo que nenhuma variável mostrou-se significativa para a produção de xilanase.

Os estudos mostraram que a proporção, ou seja, a adição da casca de maracujá, um substrato rico em pectina, não influenciou significativamente a síntese das enzimas lignolíticas. Contudo, as sínteses enzimáticas mostraram-se mais expressivas, em especial no ensaio 7, 


\section{9 a 22 de outubro de 2014 \\ Florianópolis/SC}

gerando $35 \mathrm{U} / g$ de atividade. Esta condição obteve resultados mais expressivos que o encontrado por Silva (2011), onde usando a casca de soja como substrato alcançou produção máxima de xilanase de 24,46 (U/g) e de Pereira (2011), 0,192 U/mL. Todavia, a atividade de avicelase, quando comparada aos dados de Casciatori et. al. (2012), que utilizaram bagaço de cana-deaçúcar e farelo de trigo, com produção entre 343 e $635 \mathrm{U} / \mathrm{g}$, mostrou-se menos eficaz. Os resultados também indicaram a importância do $\mathrm{pH}$ e da umidade, sendo necessário estudos mais aprofundados para um melhor controle destas variáveis.

\section{CONCLUSÃO}

Manter as condições ideais para o processo fermentativo, mesmo sendo relativamente simples (temperatura e umidade), encontra dificuldades como a estabilização do $\mathrm{pH}$ do meio próximo a 5, valor onde ocorre maior atividade enzimática. Com o emprego do planejamento experimental nas análises foi possível observar quais fatores influenciaram a síntese enzimática, com resultados expressivos de ambas as enzimas em relação à literatura, mostrando que a proporção, ou seja, a adição da casca de maracujá, um substrato rico em fibras e pectina, ao sabugo de milho não influenciou significativamente a síntese das enzimas lignolíticas. Os resultados também comprovaram a importância do $\mathrm{pH}$ e da umidade, sendo necessário estudos mais aprofundados para um melhor controle destas variáveis.

\section{REFERENCIAS}

ABUD, A. K. S.; SILVA, G. F.; NARAIN, N. Caracterização de resíduos de indústria de processamento de frutas visando à produção de pectinases por fermentação semi-sólida. SINAFERM, 2007.

CASCIATORI, F. P.; CASCIATORI, P. A.; THOMÉO, J. C.; SILVA, R. Produção de celulases pelo fungo Aspergillus niger no cultivo sólido em bagaço de cana e farelo de trigo. COBEQ, 2012.

COELHO, M.A.Z.; LEITE, S.G.F.; ROSA, M.D.E.F. Aproveitamento de resíduos agroindustriais: produção de enzimas a partir da casca de coco verde. Boletim CEPPA, v.19, n.1, p. 33-42, 2001.

COUTO S.R.; SANROMÁN, M. A. Application of solid-state fermentation to food industry - A review. Journal of Food Engineering, v. 76, p. 291-302, 2006.

FUNGARO, M.H.P.; SOUZA JR, C.L.; PIZZIRANI-KLEINER, A.A.; AZEVEDO, J.A. Recurrent mutation selection to improve rennet production in Candida tsukubaensis. Revista Brasileira de Genética, v.17, p.377-382. 1994

INSTITUTO ADOLFO LUTZ. Normas Analíticas do Instituto Adolfo Lutz. São Paulo: Instituto Adolfo Lutz, 2005.

LAUFENBERG G.; KUNZ B.; NYSTROEM, M. Transformation of vegetable waste into value added products: (a) the upgrading concept; (b) practical implementations. Bioresource Technology, v. 87, p.167-198, 2003.

LOUSADA JÚNIOR, J.E., COSTA, J.M.C., NEIVA, J.N.M., RODRIGUEZ, N.M. Caracterização físico-química de subprodutos obtidos do processamento de frutas tropicais 
visando seu aproveitamento na alimentação animal. Revista Ciência Agrotécnica, v.37, p. $70-76,2006$.

MARTIN N; SOUZA S R; SILVA R; GOMES E. Pectinase production by fungal strains in solidsate fermentation using agro-industrial bioproduct. Brazilian Archives of Biology and Technology., v. 47, n. 5, p. 813-819, 2004.

MILLER, G.L. Use of dinitrosalicylic acid reagent for determination of reducing sugar. Analytical Chemistry, v.31, p.426, 1959.

OLIVEIRA, S. Aproveitamento da casca do coco verde (Cocos nucifera L.) para produção de celulases. Dissertação de Mestrado em Tecnologia de Alimentos. UFC, 2010,81p.

PANDEY, A.; SOCCOL, C.R.; MITCHELL, D.A. New developments in solid state fermentation: I - Bioprocesses and products. Process Biochemistry, v. 35, p. 1153-1169, 2000.

PEREIRA, S. A.; SILVA, L. A. O.; ALBUQUERQUE, P. M. Estudo da produção de xilanase fúngica a partir do aproveitamento do resíduo da Castanha-do-Brasil. SINAFERM, 2011.

SANTOS, J. A. N.; CARNEIRO, W. M. A.; BRAINER, M. S. C. P.; SOUZA, G. S.; SILVA, C. E. G. A agroindústria de alimentos de frutas e hortaliças no Nordeste e demais áreas de atuação do BNB: desempenho recente e possibilidades de políticas. Fortaleza: Banco do Nordeste do Brasil. Série documentos do Etene, n. 24, 2008. 324p.

SANTOS, S. F. M.; NÓBREGA, J.E.; PINTO, G.A.S.; MACEDO, G.R.; SILVA, F.L.H. Caracterização do resíduo seco do pedúnculo de caju visando sua utilização como substrato para fermentação semi-sólida, XV SINAFERM, 2005.

SILVA, D. F.; SANCHEZ, L.B. R.; ALBUQUERQUE, P. M. Estudo da Produção de Celulase e Xilanase Fúngicas em Meio Sólido Utilizando Casca de Soja como Substrato. SINAFERM, 2011.

UENOJO, M.; PASTORE, G. M. Pectinases: aplicações e perspectivas. Química Nova, v. 30, n. 2, p. 388-394, 2007.

VAN BEILEN, J.B.; LI, Z. Enzyme technology: an overview. Current Opinion in Biotechnology, v.13, n.4, p.338-344, 2002. 